\title{
Potencial antibacteriano (in vitro) do extrato metanólico da Annona muricata $\mathbf{L}$.
}

\author{
Antibacterial potential (in vitro) of methanolic extract from Annona muricata L. \\ Potencial antibacteriano (in vitro) del extracto metanólico de Annona muricata L.
}

\author{
Anny Karoline Rodrigues Batista \\ ORCID: https://orcid.org/0000-0001-9482-6679 \\ Universidade Estadual do Maranhão, Brasil \\ E- mail: karol_rodrigues.b@hotmail.com \\ Kellyane Karen Ferreira Aguiar Cesar \\ ORCID: https://orcid.org/0000-0002-4635-2410 \\ Universidade Estadual do Maranhão, Brasil \\ E-mail:kellyanekaren@outlook.com \\ Luciana Rocha Paula \\ ORCID: https://orcid.org/0000-0002-6264-7876 \\ Universidade Estadual do Maranhão, Brasil \\ E- mail: lucianapaula_99@hotmail.com \\ Francisco Laurindo da Silva \\ ORCID: https://orcid.org/0000-0001-6837-4509 \\ Universidade Estadual do Maranhão, Brasil \\ E-mail: flspb@yahoo.com.br \\ Haysha Laianne Oliveira Raposo \\ ORCID: https://orcid.org/0000-0003-1391-7507 \\ Universidade Estadual do Maranhão, Brasil \\ E-mail:ysharaposo@gmail.com
}

\begin{abstract}
Resumo
A resistência bacteriana a antibióticos tornou-se mundialmente um sério problema de Saúde Pública atingindo milhares de pessoas. Assim, vê-se a necessidade de buscar formas alternativas no combate das mesmas. Portanto, essa pesquisa objetivou verificar o efeito antimicrobiano do extrato da Annona muricata L. frente a cepas ATCC de Escherichia coli, Klebsiella pneumoniae, Pseudomonas aeruginosa e Staphylococcus aureus. Realizou-se a coleta do material e a obtenção dos extratos, posteriormente houve a preparação das cepas bacterianas para os testes de suscetibilidade. Os testes prosseguiram em três etapas: extratos brutos, extratos fracionados quimicamente e testes com diluições seriadas. Verificou-se atividade antibacteriana da graviola frente a todas as cepas testas sendo o resultado mais significante referente ao extrato bruto do fruto frente a cepa da $E$. coli com halo igual a $22 \mathrm{~mm}$. Em relação aos testes com os extratos já purificados, as frações provenientes do fruto tiverem ação mais relevantes. A fração de Hexano correspondeu em resultados mais expressivos obtendo halos igual a $28 \mathrm{~mm}, 26 \mathrm{~mm}$ e $37 \mathrm{~mm}$ frente as cepas de E. coli, K. pneumoniae, e $S$. aureus respectivamente. Quanto aos testes relacionados as diluições seriadas observamos que a partir da diluição de 1/10 os extratos já não possuíram nenhuma atividade inibitória sobre as bactérias em estudo. Contudo, esses resultados demonstram o potencial do extrato da graviola, em especial do fruto, como fonte de compostos antibacterianos. No entanto, é válido continuar pesquisas mais avançadas com a Annona muricata.
\end{abstract}

Palavras-chave: Extratos vegetais; Bactérias; Teste de suscetibilidade.

\begin{abstract}
Bacterial resistance to antibiotics has become a serious public health problem worldwide, affecting thousands of people. Thus, there is a need to seek alternative ways to combat them. Therefore, this research aimed to verify the antimicrobial effect of the extract of Annona muricata L. against ATCC strains of Escherichia coli, Klebsiella pneumoniae, Pseudomonas aeruginosa and Staphylococcus aureus. The material was collected and the extracts were obtained, then the bacterial strains were prepared for susceptibility testing. The tests proceeded in three stages: crude extracts, chemically fractionated extracts and tests with serial dilutions. Soursop antibacterial activity was observed against all strains tested, the most significant result being the crude extract of the fruit against the strain of $E$. coli with a halo equal to $22 \mathrm{~mm}$. In relation to the tests with the extracts already purified, the fractions from the fruit have more relevant action. The Hexane fraction corresponded to the most expressive results, obtaining halos equal to $28 \mathrm{~mm}, 26 \mathrm{~mm}$ and $37 \mathrm{~mm}$ against the strains of E. coli, K. pneumoniae, and S. aureus respectively. As for the tests related to serial dilutions, we observed that after the 1/10 dilution, the extracts no longer had any inhibitory activity on the bacteria under study. However, these results demonstrate the potential of the soursop extract, especially the fruit, as a source of antibacterial compounds. However, it is worthwhile to continue more advanced research with Annona muricata.
\end{abstract}

Keywords: Plant extracts; Bacteria; Susceptibility test. 


\begin{abstract}
Resumen
La resistencia bacteriana a los antibióticos se ha convertido en un grave problema de salud pública en todo el mundo, que afecta a miles de personas. Por tanto, es necesario buscar formas alternativas de combatirlos. Por tanto, esta investigación tuvo como objetivo verificar el efecto antimicrobiano del extracto de Annona muricata L. frente a cepas ATCC de Escherichia coli, Klebsiella pneumoniae, Pseudomonas aeruginosa y Staphylococcus aureus. Se recogió el material y se obtuvieron los extractos, luego se prepararon las cepas bacterianas para las pruebas de susceptibilidad. Las pruebas se desarrollaron en tres etapas: extractos crudos, extractos fraccionados químicamente y pruebas con diluciones seriadas. Se observó actividad antibacteriana de guanábana frente a todas las cepas ensayadas, siendo el resultado más significativo el extracto crudo de la fruta frente a la cepa de $E$. coli con un halo igual a $22 \mathrm{~mm}$. En relación a las pruebas con los extractos ya purificados, las fracciones de la fruta tienen una acción más relevante. La fracción Hexano correspondió a los resultados más expresivos, obteniendo halos iguales a $28 \mathrm{~mm}, 26 \mathrm{~mm}$ y $37 \mathrm{~mm}$ frente a las cepas de E. coli, K. pneumoniae y $S$. aureus respectivamente. En cuanto a las pruebas relacionadas con las diluciones seriadas, observamos que después de la dilución 1/10, los extractos ya no tenían actividad inhibidora sobre las bacterias en estudio. Sin embargo, estos resultados demuestran el potencial del extracto de guanábana, especialmente la fruta, como fuente de compuestos antibacterianos. Sin embargo, vale la pena continuar con investigaciones más avanzadas con Annona muricata.
\end{abstract}

Palabras clave: Extractos de plantas; Bacterias; Prueba de susceptibilidad.

\title{
1. Introdução
}

A resistência bacteriana a antibióticos tornou-se mundialmente um sério problema de Saúde Pública atingindo milhares de pessoas (Silva \& Aquino, 2018). Para o tratamento das infecções causadas por bactérias é necessário o uso de antibióticos pois os mesmos, além de extinguir o microrganismo, preservam a saúde humana. Atualmente, vê-se a necessidade dos governos em incentivar o desenvolvimento de novos antibióticos de baixo custo adaptados as necessidades mundial que sejam eficazes e seguros (Guimarães, Momesso \& Pupo, 2010).

No entanto, é desafiador encontrar um ponto de compensação entre esses dois fatores visto que, a resistência bacteriana tem crescido significativamente nos últimos anos mais do que o desenvolvimento de novos antibióticos, ocasionando assim, impacto negativo sobre o tratamento das doenças causadas por bactérias, o que gera necessidade urgente de novas abordagens terapêuticas. Dessa forma, o desenvolvimento de substâncias provenientes de vegetais têm sido uma alternativa por possuírem metabólitos com várias propriedades e têm auxiliado em resultados significativos e eficientes em tratamentos terapêuticos que atuem inibindo a resistência microbiana ou o seu crescimento (Santana et al., 2016).

Segundo a Organização Mundial da Saúde (OMS), parte da população dos países emergentes depende da medicina tradicional, ou seja, do uso de plantas medicinais para sua atenção básica (Brasil, 2016). Com base no conhecimento empírico, observado pelo uso tradicional, a comunidade científica deu iniciativa para pesquisas sobre os efeitos das plantas medicinais através dos extratos com estudos de bioatividade. Assim, a atividade antimicrobiana de extratos vegetais pode representar uma fundamental alternativa terapêutica e medicinal quando comparada aos agentes químicos utilizados rotineiramente, contra os quais os micro-organismos já desenvolveram inúmeros mecanismos de resistência (Dutra et al. 2016).

Estudos com várias espécies de plantas são desenvolvidos, inclusive com a espécie da Annona muricata L., popularmente conhecida como graviola (Beneval et al., 2016). A gravioleira vem sendo pesquisa há, pelo menos, quarenta anos devido a suas substâncias bioativas. A folha da gravioleira contém compostos com ação antimicrobiana como o tetrahidrofurano (THF) anonacina (Moghadamtousi et al.,2015). Na medicina popular, partes da gravioleira como: cascas, raízes, folhas, polpa e sementes rica em compostos bioativos, têm sido utilizadas para o tratamento de várias doenças humanas devido às suas propriedades terapêuticas tais como: antibacteriana, antirreumática, antiflamatória, calmante, diurética, inseticida, efeito imunossupressor, antiparasitária e entre outras ações, com destaque na sua atividade anticancerígena devido a sua capacidade citotóxica. Além de ser indicada para disenteria, edema, febre, gripe, tosse, hipertensão, dor, emagrecimento, vermes intestinais, tratamento renal, etc. (Dani, Calloni, Salvador \& Spada, 2010). Destacando -se ainda seu potencial para inibir células resistentes a múltiplas drogas, dessa forma, tem atraído interesse científico (Alfaia \& Almeida, 2016). 
Por tanto, levando em consideração o conhecimento do crescimento da resistência aos antibióticos, foram selecionadas cepas bacterianas ATCC de Pseudomonas aeruginosa, Escherichia coli, Klebsiella pneumoniae e Staphylococcus aureus para esse estudo. Esses microrganismos são responsáveis por inúmeras infecções, complicações e surtos hospitalares (OMS, 2017). Devido a este fato, faz- se imprescindível examinar a atividade antimicrobiana interativa de extratos vegetais como um meio promissor e alternativo na eliminação dos microrganismos resistentes. Assim, o presente estudo resulta em testar os extratos vegetais da folha e fruto da Annona muricata L. com a finalidade de descobrir a capacidade antimicrobiana sobre esses patógenos.

\section{Metodologia}

\subsection{Coleta dos espécimes vegetais}

O espécime vegetal de Annona muricata foi coletado na localidade Serra do Gavião, especificamente no sítio São Joaquim, com área aproximada de 3,0 hectares, localizado a $25 \mathrm{~km}$ de distância da cidade de Teresina, na região centro norte. Foi coletado aproximadamente $1 \mathrm{~kg}$ das seguintes partes: folha e fruto, valor estimado como o suficiente para transformação do material bruto em material refinado, ou seja, obtenção dos extratos metanólicos, para serem utilizados nos testes contra as cepas bacterianas. Segundo a Farmacopeia Brasileira (2019), a seleção das espécies vegetais que devem fazer parte do estudo de caracterização com finalidade microbiológica são aquelas que apresentem alguma atividade farmacológica utilizadas na medicina popular.

\subsection{Preparo e identificação do vegetal}

A espécie de vegetal citada anteriormente foi coletada, prensada, feito exsicatas, identificadas e depositadas no Herbário Aluízio Bittencourt pertencente ao Laboratório de Botânica da Universidade Estadual do Maranhão (LABIVE/UEMA/CESC) (número de tombamento: HABIT 3569).

\subsection{Obtenção dos extratos}

Os extratos foram obtidos no Laboratório de Química da Faculdade Integral Diferencial (FACID), seguindo as orientações recomendadas pela Farmacopeia Brasileira (2019). Após coleta, os vegetais foram postos para secagem à sombra, sendo expostas ao ambiente por 4 horas diárias. A trituração dos vegetais foi realizada em moinho de facas até a condição de pó. Ao pó foi adicionado solvente metanol que ficou em repouso por 21 dias com agitação diária por 30 minutos. Após esse período, o material foi filtrado e posto em evaporador rotativo a $40^{\circ} \mathrm{C}$ para retirada de todo o solvente.

\subsection{Amostras Microbianas}

As cepas bacterianas foram mantidas em repiques sucessivos em meio de cultura Tryptic Soy Aga (TSA) até utilização nos testes de suscetibilidade. A Sociedade Brasileira de Microbiologia recomenda o uso de cepas da American Type Culture Colletion (ATCC) para o controle de qualidade dos trabalhos com bactérias. Nesse trabalho foram utilizadas cepas de Klebsiella pneumoniae ATCC 7853, Escherichia coli ATCC 25922, Pseudomonas aeruginosa ATCC 1705 e Staphylococcus aureus ATCC 25923 adquiridas comercialmente. Essas cepas estavam liofilizadas, antes dos testes, foram hidratadas em solução salina e mantidas em repouso por $1 \mathrm{~h}$. Após esse tempo foram semeadas em placas de Petri com TSA. As placas foram incubadas em estufa BOD (Demanda Bioquímica de Oxigênio) por 48 h.

\subsubsection{Preparo dos meios de cultura para os testes de suscetibilidade}

As placas para os testes de suscetibilidade foram formadas de duas camadas. Para a formação da primeira, composta de ágar-ágar, foram utilizados 10,6 gramas do ágar diluídos em $300 \mathrm{ml}$ de água destilada, conforme recomendação do fabricante. 
Essa mistura foi agitada suavemente e levada ao micro-ondas até dissolução total do meio de cultura. Alíquotas de $15 \mathrm{ml}$ desse meio foram postas em tubos de ensaio e esterilizadas na autoclave à temperatura de $120^{\circ} \mathrm{C}$ por 15 minutos. Após esterilização as alíquotas foram entornadas em placas de Petri, com tamanho de 90 x $15 \mathrm{~mm}$ descartáveis esterilizadas (Pleion $®$ ), as quais foram postas em repouso até solidificação do meio de cultura. A segunda camada fora composta de ágar Muller-Hinton. Para tanto, 3,6g de soluto foram diluídas em $300 \mathrm{ml}$ de água destilada. Alíquotas de $13 \mathrm{ml}$ desse meio foram postas em tubos de ensaio e esterilizadas na autoclave à temperatura de $120^{\circ} \mathrm{C}$ por 15 minutos.

\subsubsection{Preparo do inóculo bacteriano}

Por meio de uma alça de platina esterilizada foi realizada a inoculação dos microrganismos recentemente repicados, em tubos de ensaio com $1 \mathrm{ml}$ de solução salina e após essa inoculação foi obtido a turbidez com base na escala 0,5 de Mac Farland (MF).

\subsection{Preparo das placas para a realização dos testes de suscetibilidade}

Para esse teste, $1 \mathrm{ml}$ da suspensão bacteriana foi adicionada aos $13 \mathrm{ml}$ de ágar Muller-Hinton, mantido à temperatura de $45{ }^{\circ} \mathrm{C}$ no banho-maria. A segunda parte foi entornada sobre a primeira e poços foram confeccionados na segunda camada, mediante a utilização de ponteiras plásticas esterilizadas de 4,0 mm de diâmetros.

\subsection{Avaliação da atividade antibacteriana dos extratos vegetais pelo método de difusão em ágar}

Todos os ensaios foram realizados em triplicata utilizando-se cepas provenientes da American Type Culture Collection (ATCC). A determinação da atividade antibacteriana foi realizada pela técnica da difusão em ágar em poços, segundo Grove e Randall (1955). Como controle positivo foi utilizado um antibiótico de referência o Cloranfenicol na concentração de

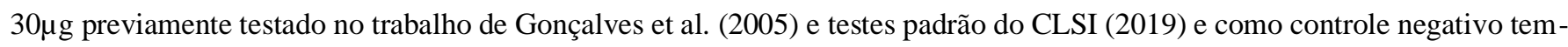
se o solvente utilizado na diluição dos extratos (Dilmetilsulfóxido - DMSO). Nos poços formados na segunda camada foram adicionados $40 \mu \mathrm{L}$ dos extratos testados, seguindo metodologia semelhante à de Alves et al. (2008). As placas foram incubadas a temperatura de $36^{\circ} \mathrm{C}$ em estufa BOD por um período de 48h. Após período de incubação foi realizada a leitura dos resultados, que consistiu em medir o diâmetro dos halos de inibição que foram formados incluindo o diâmetro dos poços. Os halos de inibição do crescimento bacteriano foram medidos em milímetros, com auxílio de uma régua milimetrada. Vale ressaltar que o Instituto de Padrões Clínicos e Laboratoriais (The Clinical and Laboratory Standards Institute) define a ação antibacteriana em susceptível (halos de inibição maiores ou iguais a $18 \mathrm{~mm}$ ), intermediário (halos de inibição entre $13 \mathrm{a} 17 \mathrm{~mm}$ ) e resistentes (valores menores ou iguais $12 \mathrm{~mm}$ de halo de inibição) (CLSI, 2019). Foi considerado, como resultado final de cada extrato, a média das três medidas (Parekh \& Chanda, 2007, Santos et al., 2007).

\subsection{Fracionamento químico dos extratos vegetais}

Após comprovada atividade antimicrobiana dos extratos, os mesmos foram submetidos a um processo de partição líquido-líquido com solventes de polaridades crescentes, como hexano, butanol e acetato de etila visando uma semi-purificação das substâncias através de suas polaridades (Filho \& Yunes, 1998). Em $1 \mathrm{~mL}$ dos extratos metanólicos da folha e fruto da Anonna muricata foram adicionados $20 \mathrm{ml}$ dos solventes (acetato de etila, butanol e hexano). Cada fração foi colocada em uma bureta e esperado a total decantação da fração de interesse para os testes de suscetibilidade, seguindo metodologia descrita no teste de difusão em ágar. 


\subsection{Determinação da atividade antimicrobiana em função da concentração dos extratos em diluições seriadas}

A determinação da atividade antimicrobiana de extratos em diluição seriada foi realizada segundo a metodologia modificada conforme recomendada pelo CLSI, 2019. Utilizou-se $100 \mu \mathrm{L}$ dos extratos vegetais fracionados acrescentados em $900 \mu \mathrm{L}$ de DMSO e diluições seriadas foram realizadas nas concentrações de 1/10, 1/100 e 1/1000. As placas testes foram confeccionadas seguindo metodologia previamente determinada. Em cada orifício da placa teste foram micropipetados $40 \mu \mathrm{L}$ de cada extrato em diluição seriada. As placas foram incubadas a $36^{\circ} \mathrm{C}$ por $48 \mathrm{~h}$ sem agitação (Alves et al., 2008). Após período de incubação foi realizada a leitura dos resultados, que consistiu em medir o diâmetro dos halos de inibição que foram formados.

\subsection{Análises estatísticas}

Os conjuntos de dados foram submetidos aos testes de normalidade (Shapiro-Wilk) e homogeneidade (Levene). Os dados são referentes aos halos de inibição $(\mathrm{em} \mathrm{mm})$ correspondentes à atividade antimicrobiana dos extratos vegetais. Como estes não se ajustaram à distribuição normal e nem à igualdade de variâncias, análises não-paramétricas correspondentes foram utilizadas.

Para examinar se houve diferença nas medianas dos grupos de extratos comparados foi utilizada as análises de MannWhitney $(M W)$ para os testes com duas variáveis (Tabela 1) e Kruskal-Wallis (KW) para os testes com três variáveis (Tabela 2), levando em consideração $\mathrm{p}=5 \%$ ( $\mathrm{p}<0,05$ ). Os testes estatísticos foram realizados com o software $\mathrm{R}$ versão 4.0.3.

\section{Resultados e Discussão}

Na excussão da pesquisa, utilizou-se extratos metanólicos brutos da folha e fruto da gravioleira. Através dos testes, verificou-se atividade antibacteriana dos extratos contra as cepas testas, exceto o extrato da folha contra as cepas da $E$. coli e $K$. pneumoniae. Por outro lado, o extrato do fruto manifestou ação antibacteriana contra todas as cepas. Embora o extrato do fruto tenha ação contra a cepa da $K$. pneumoniae formando halo de inibição (equivalente a $12 \mathrm{~mm}$ ) e o extrato da folha tenha desempenhado ação frente a cepa de S. aureus formando halo equivalente a $11 \mathrm{~mm}$ esses valores conforme o CSLI de 2019 não são suficientes caracterizando essas cepas resistentes aos extratos (Tabela 1). 
Tabela 1: Demonstração da atividade antimicrobiana dos extratos vegetais metanólicos (brutos) da graviola em relação as cepas bacterianas ATCC. Caxias-MA, 2021. N=04.

\begin{tabular}{llll}
\hline Microrganismos & Extratos & $\begin{array}{c}\text { Halos } \\
(\mathbf{m m})\end{array}$ & CLF \\
\hline Escherichia coli & Folha & 0 & 37 \\
& Fruto & 22 & 25 \\
Klebsiella pneumoniae & Folha & 0 & 35 \\
& Fruto & 12 & 28 \\
Pseudomonas aeruginosa & Folha & 14 & 13 \\
& Fruto & 11 & 28
\end{tabular}

\section{Dados estatísticos:}

$$
\mathrm{MW} / \mathrm{p}=0.2857^{*}
$$

Medidas dos halos em mm; CLF= cloranfenicol (valor dos halos em mm); MW= Mann-Whitney; $\mathrm{p}=$ valor de p; * valor de p não significativo. Fonte: Autores.

Conforme a Tabela é possível verificar diferenças nas atividades antibacterianas entre os extratos. No entanto é importante destacar que o resultado foi mais expressivo em relação a utilização do extrato do fruto frete a cepa da E. coli. Dado a importância desse microrganismo associado a vários processos infecciosos em humanos e com base nos resultados obtidos, o fruto da graviola contém princípio ativo que pode ser isolado e utilizado como ferramenta terapêutica auxiliar no controle da $E$. coli.

Haro, Utami e Sitompul (2014) ao pesquisar sobre o extrato metanólico da graviola demonstraram atividade antibacteriana sobre os microrganismos testados justificando tais ações relacionadas aos taninos e flavonoides. Sendo assim, a ação dos taninos responsáveis por desfazer a membrana citoplasmática bacteriana através da coagulação de suas proteínas e os flavonoides por romper a permeabilidade da parede celular, caracterizando uma ação sinérgica entre os componentes. Estudos realizado por Ali e colaboradores demonstraram que um dos principais tipos de flavonoides com ação antibacteriana se trata da crisina (5 - 7 - dihidroxiflavona) a qual é capaz de inibir o crescimento de bactérias Gram - negativas tais como $E$. coli e $P$. aeruginosa. Já a atividade contra as Gram- positivas se daria a um grupo adicional em C - - 6 presente nas moléculas de crisina (Ali et al., 1998). Outro estudo realizado por Bylka e colaboradores, evidenciam que a flavona apigenina apresenta atividade contra P. aeruginosa, E. coli e B. subtilis. Um outro estudo, também realizado por Bylka e colaboradores, provou que a flavanona naringenina é ativa contra E. coli, S. aureus e E. faecalis (Bylka et al.,2004). Em resumo, o efeito antibacteriano dos flavonoides deve-se à atribuição de grupos fenólicos hidroxilo que apresentam afinidade para as proteínas e, por essa razão, agem como inibidores de enzimas bacterianas, assim como interferem nas suas vias de síntese (Alcaráz et al., 2000; Àvila, et al., 2008; Li et al., 2012 Sato et al., 1995).

Com relação aos taninos, existem duas classificações: taninos hidrolisáveis, que, após hidrólise, produzem carboidratos e ácidos fenólicos e os taninos condensados ou não hidrolisáveis, que são resistentes à hidrólise, e são oligômeros dos grupos flavan-3-ols (catequina) ou flaven 3,4-diols (leucoantocianidina). Dentre esses tipos de taninos os mais presentes nas plantas, 
tanto nas folhas quanto nos frutos, são os hidrolisáveis (Salunkhe et al, 1990). Os taninos agem precipitando as proteínas das células superficiais das mucosas e dos tecidos, formando uma capa protetora, inibindo enzimas, causando uma ruptura da membrana plasmática e privação do substrato microbiano por formar um complexo tanino-proteína e/ou polissacarídeo, impedindo assim, o desenvolvimento de microrganismos (Haslam1996; Rodrigues et al.2014).

Embora os estudos apontam atividade antibacteriana dos compostos químicos que possam estar persentes nos extratos da graviola frente aos microrganismos Gram-negativos, notamos, de acordo com os dados da Tabela 1, a não atividade antibacteriana do extrato da folha frente as cepas da E. coli e K. pneumoniae que corrobora com estudos realizados por Afroz et al. (2019) onde foi testado extrato metanólico de A. muricata que não exibiu nenhuma atividade antibacteriana eficaz contra as bactérias testadas. Essa falta de inibição do extrato pode ser explicada pela diferença de composição e estrutura da parede celular já que as bactérias Gram-negativas possuem parede celular mais resistente constituídas por múltiplas camadas de lipoproteína, lipossacarídeo e peptidoglicano com alto teor de lipídeos. Assim, os antibióticos não são capazes de atravessar efetivamente a barreira lipídica da camada externa dessas bactérias (Guimarães, Momesso \& Pupo, 2010).

Embora as bactérias Gram-negativas serem mais resistentes, foi observado halos de inibição contra a cepa de $P$. aeruginosa, descrito anteriormente (Tabela 1). Esse resultado se assemelha com os resultados encontrado no trabalho de Galvão, et al (2016), o qual realizou testes como a Annona glabra onde foi comprovada a atividade antibacteriana frente a cepa de $P$. aeruginosa. Essa ação antibacteriana foi relacionada aos flavonoides.

Em relação a cepa de $S$. aureus já mencionado anteriormente, o extrato da folha não caracterizou um nível de inibição aceitável. Estudos feitos por Silva, Antunes e Catão (2011) verificaram a inatividade antibacteriana, trabalhando com extratos hidroalcoólico e aquoso de cascas, folhas e fruto da A. muricata, sugerindo que a não atividade dos extratos testados pode estar relacionada a alguns fatores como a dificuldade de difusão no meio de cultura, solvente utilizado para extração, a temperatura, tempo de incubação e microrganismos testados.

Após a testagem dos extratos metanólicos (brutos) do fruto e da folha da A. muricata foi realizado a semi-purificação dessas substâncias utilizando solventes de polaridade crescentes como: Acetato de Etila, Butanol e Hexano visando, assim, o isolamento de substâncias ativas.

Segundo Fillho et al. (1998), o Acetato de Etila isola flavonoides, taninos, xantonas, ácidos triterpênicos, saponinas e compostos fenólicos em geral. O Butanol isola flavonoides, glicosilados, taninos, saponinas e carboidratos. Na literatura é notória a utilização do Hexano no isolamento das seguintes substâncias: esteroides, terpenos e acetofenonas. Dessa forma, utilizou-se essas substâncias químicas no fracionamento do extrato bruto da graviola e após fracionamentos, frações foram utilizadas em testes de suscetibilidade sobre cepas ATCC de microrganismos. Pode-se observar que testes utilizados com alíquotas obtidas dos fracionamentos provenientes do fruto tiverem ação mais significantes. Assim, a fração de Hexano correspondeu a resultados mais expressivos contra a maioria das cepas testadas obtendo halos igual a $28 \mathrm{~mm}, 26 \mathrm{~mm}$ e $37 \mathrm{~mm}$ frente as cepas de E. coli, $K$. pneumoniae, e S. aureu respectivamente. A fração de Butanol também teve destaque frente as cepas de E. coli e K. pneumoniae com halos em ambas cepas igual a 30mm, com relação a fração de Acetato de Etila, também observamos um resultado mais significante somente frente a cepa de $P$. aeruginosa com halo equivalente a $25 \mathrm{~mm}$ (Tabela 2).

Os resultados desse estudo corroboram com o estudo feito por Dolab et al (2018) onde foram testados os extratos da Annona emarginata e observado que o extrato da fruta também teve atividade antibacteriana muito forte sendo ativo contra as três cepas bacterianas (S. aureus sensível à meticilina (MSSA) ATCC 25923, S. aureus resistente à meticilina (MRSA) ATCC 43300 e K. pneumoniae). 
Tabela 2: Perfil de suscetibilidade das cepas microbianas de E. coli, K. pneumoniae, P. aeruginosa e $S$. aureus frente a extratos brutos do fruto da graviola após fracionados quimicamente. Caxias-MA, 2021. N=04/06.

\begin{tabular}{|c|c|c|c|c|c|c|}
\hline \multirow[t]{2}{*}{ Microrganismos } & \multicolumn{6}{|c|}{$\begin{array}{l}\text { Extratos Fracionados } \\
(\mathrm{mm})\end{array}$} \\
\hline & AEF & AEFR & $\mathbf{B F}$ & BFR & $\mathbf{H F}$ & HFR \\
\hline Escherichia coli & NT & 25 & NT & 30 & NT & 28 \\
\hline Klebsiella pneumoniae & NT & 0 & NT & 30 & NT & 26 \\
\hline Pseudomonas aeruginosa & 0 & 25 & 0 & 0 & 12 & 0 \\
\hline Staphylococcus aureus & 0 & 12 & 0 & 15 & 10 & 37 \\
\hline
\end{tabular}

\section{Dados estatísticos:}

$$
\mathrm{KW} / \mathrm{p}=0.214^{*}
$$

mm= Medida em milímetros; $\mathrm{AEF}=$ Acetato de Etila Folha; AEFR = Acetato de Etila Fruto; $\mathrm{BF}=\mathrm{Butanol}$ Folha; $\mathrm{BFR}=\mathrm{Butanol}$ Fruto; HF = Hexano Folha; Hexano Fruto; NT= não testável; KW= Kruskal-Wallis; p= valor de p; * valor de p não significativo.

Fonte: Autores.

Ainda de acordo com os dados da tabela, observando o extrato da folha, somente a fração de Hexano exibiu inibição nas cepas testadas embora essa ação inibitória não tenha sido de grande significância. Apesar disso, o presente estudo permitiu observar que a gravioleira, em especial seu fruto, possui importante ação antibacteriana o que torna essa pesquisa de grande relevância visto que dentre os microrganismos, as bactérias são os mais perigosos da atualidade e estão se tornando uma ameaça mundial. As doenças infecciosas bacterianas são de grande preocupação tanto dos países em desenvolvimento quanto dos desenvolvidos, assim as plantas medicinais se tornaram um meio promissor no tratamento dessas infecções devido a sua rica fonte de atividade antimicrobiana e de menor custo (Debalke, Birhan, Kinubeh \& Yayeh, 2018).

Mediante a esses testes foi realizado a diluição seriada (em $\mu \mathrm{L})$ dos extratos fracionados quimicamente seguindo proporções de 1/10, 1/100 e 1/1000 para assim verificar qual concentração mínima de extrato é capaz de inibir os microrganismos. Nenhuma das frações demostrou atividade contra as cepas testas. Dessa forma, fica evidente que a partir das concentração de 1/10, os extratos já não conseguem inibir o crescimento bacteriano.

\section{Conclusão}

De acordo com resultados encontrados neste estudo, constatou-se que a graviola apresenta grande efeito antibacteriano principalmente quando observado o potencial antibacteriano do extrato do fruto, no entanto, é válido continuar pesquisas mais avançadas com a Annona muricata e seu potencial antibacteriano frente a outros microrganismos, tendo em vista o potencial medicinal desta planta que já é conhecido pela medicina popular e também de conhecimento da comunidade científica como demonstra os estudos sobre alguns dos seus compostos bioativos.

Assim, sugere-se que a graviola pode ser uma espécie com perspectivas promissoras para serem melhor aproveitadas como nutracêutico ou com finalidades terapêuticas na indústria farmacêutica. 


\section{Referências}

Alcaráz, L. E, Blanco, S. E., Puig, O. N., Tomás, F., \& Ferreti, F. H. (2000). Antibacterial Activity of Flavonoids Against Methicilin - resistant Staphylococcus aureus strains. J. theor. Biol. 205, $231-240$.

Ali, R., Houghton, P., Raman, A., \& Hoult, J. (1998). Antimicrobial and anti-inflammatory activities of extracts and constituents of Oroxylum indicum. Phytomedicine, 5, 375-81.

Alfaia, D., \& Almeida, S. (2016). Avaliação fitoquímica, análise citotóxica e antimicrobiana do extrato bruto etanólico das folhas de Annona muricata L. (Annonaceae). Biota Amazônia (Biote Amazonie, Biota Amazonia, Amazonian Biota), 6(1), 26-30. http://dx.doi.org/10.18561/2179-5746/biotaamazonia. 6 (1), 20-25

Alves, E. G., Vinholis, A. H. C., Casemiro, L. A., Furtado, N. A. J. C., Silva, M. L. A., Cunha, W. R., \& Martins, C. H. G. (2008). Estudo comparativo de técnicas de triagem para avaliação da atividade anti--bacteriana de extratos brutos de vegetais espécies e substâncias puras. Química Nova, 31 (5), 12241229. https://doi.org/10.1590/S0100-40422008000500052

Afroz, N., Hoq, A., Jahan, S., Islam, M., Ahmed, F., et al. (2019). Methanol soluble fraction of fruits of Annona muricata possesses significant antidiarrheal activities. Heliyon, 6(1), e03112. doi.org/10.1016/j.heliyon.2019.e03112

Brasil. Ministério da Saúde. Ministério da Saúde. (2016). Política e Programa Nacional de Plantas e Fitoterápicas. Ministério da Saúde

Brasil. Ministério da Saúde. Farmacopeia Brasileira. (2019). Agência Nacional de Vigilância Sanitária. Brasília - DF: Anvisa (6)2, https://www.gov.br/anvisa/ptbr/assuntos/farmacopeia/farmacopeia-brasileira/arquivos/7989json-file-1

Beneval, B., Monteiro, E. B., Lemos, Á. S., Junior, I. C. B., Oliveira, F. E., Menezes, D. R. A., Irwin, R., \& Kerntopf, M. R. (2016). Estudo etnofarmacológico comparativo na região do Araripe da Annona muricata L. (Graviola). Revista Cubana de Plantas Medicinales, 21 (1), 919.http://scielo.sld.cu/scielo.php?script=sci_arttext\&pid=S102847962016000100002\&lng=es\&tlng=pt

Bylka, W., Matlawska, I., \& Pilewski, N. A. (2004). Natural Flavonoids as Antimicrobial Agents. Mylan School of Pharmacy, 7(2), 24 - 31.

Clinical Laboratory Standards Institute (CLSI). (2019) Performance standards for antimicrobial susceptibility testing: twenty-first informational supplement. NCCLS document M100-521, 34(1)

Dani, C., Aginoni, J. C., Calloni, C., Salvador, M., \& Spada, P. D. S. (2010). Viabilidade celular de cultura de linfócitos tratados com Annona muricata L. Biociências e Saúde, 12(24), 95-101. http://dx.doi.org/10.15602/1983-9480/cmbs. 12 (24), 95-101.

Debalke, D., Birhan, M., Kinubeh, A., \& Yayeh, M. (2018). Assessments of Antibacterial Effects of Aqueous-Ethanolic Extracts of Sida rhombifolia's Aerial Part. The Scientific World Journal, (Artigo ID 8429809), 1-8. https://doi.org/10.1155/2018/8429809

Dolab, J., Lima, B., Spaczynska, E., Kos, J., Cano, N., Feresin, G, Tapia, A, Garibotto, F, Petenatti, E, Olivella, M, Musiol, R, Jampilek, J., \& Enriz, R (2018). A atividade antimicrobiana de Annona emarginata (Schltdl.) H. Rainer e os compostos isolados mais ativos contra bactérias clinicamente importantes. Moléculas, 23 (5), 1187. 10.3390 / moléculas23051187

Dutra, F. S. G., Carlos, L. A., Motta, O. V., Vianna, A. P., \& Pereira, S. M. F. (2016). Atividade antimicrobiana de extratos vegetais frente à bactérias de importância médica. Biológicas \& Saúde, 6(20). https://doi.org/10.25242/88686202016965

Filho, C. V., \& Yunes, R. A. (1998). Estratégias para a obtenção de compostos farmacologicamente ativos a partir de plantas medicinais: conceitos sobre modificação estrutural para otimização da atividade. Química Nova, 21 (1), 99-105. https://doi.org/10.1590/S0100-40421998000100015

Galvão, S. S., Monteiro, A. S., Siqueira, E. P., Bomfim, M. R. Q., Souza, M. V. D., Ferreira, G. F., Denadai, A. M. L., Santos, A. R. C., Santos, V. L., Fagundes, E. M. S., Fernandes, E. S., \& Neto, V. M. (2016). Annona glabra Flavonoids Act As Antimicrobials by Binding to Pseudomonas aeruginosa Cell Walls. Frontiers in microbiology, 7, 2053. https://doi.org/10.3389/fmicb.2016.02053

Grove, D. C., \& Randall, W. A. (1955). Assay methods of antibiotics: A laboratory manual. (2a ed.). Medical Encyclopedia Inc.

Gonçalves, A. L., Filho, A. A., \& Menezes, H. (2005). Estudo comparativo da atividade antimicrobiana de extratos de algumas árvores nativas. Arq. Inst. Biol. São Paulo, 72 (3), 353-358. www.biologico.sp.gov.br/docs/arq/V72_3/goncalves.PDF

Guimarães, D. O., Momesso, L. S., \& Pupo, M. T. (2010). Antibióticos: importância terapêutica e perspectivas para a descoberta e desenvolvimento de novos agentes. Química Nova, 33(3), 667-679. https://doi.org/10.1590/S0100-40422010000300035

Haro, G, Utami, N. P., \& Sitompul, E. (2014). Study of The Antibacterial Activities of Soursop (Annona muricata L.) Leaves. International Journal of Pharm Tech Research, (6)2, 575-581.

Haslam E. (1996). Natural polyphenols (vegetable tannins) as drugs: possible modes of action. Journal of natural products, 59(2), 205-215. https://doi.org/10.1021/np960040+

Li, Y, Luo, Y, Hu, Y, Zhu, D. D., Zhang, S, Liu, Z. J., Gong, H B., \& Zhu, H. L. (2012). Design, synthesis and antimicrobial activities of nitroimidazole derivaties containing 1,3,4 - oxadiazole scaffold as FabH inhibitors. Bioorganic and Medicinal Chemistry, 20, 4316 - 4322.

Moghadamtousi, S. Z., Fadaeinasab, M., Nikzad, S., Mohan, G., Ali, H. M., e Kadir, H. A. (2015). Annona muricata (Annonaceae): A Review of Its Traditional Uses, Isolated Acetogenins and Biological Activities. International journal of molecular sciences, 16(7), 15625-15658. https://doi.org/10.3390/ijms160715625 
Research, Society and Development, v. 10, n. 5, e33510514950, 2021

(CC BY 4.0) | ISSN 2525-3409 | DOI: http://dx.doi.org/10.33448/rsd-v10i5.14950

Organização mundial da saúde. (2017). OMS publica lista de bactérias para quais se necessitam novos antibióticos urgentemente. https://www.paho.org/bra/index.php?option=com_content\&view=article\&id=5357:oms-publica-lista-de-bacterias-para-as-quais-se-necessitamnovos-antibioticos-urgentemente\&Itemid $=812$

Parekh J., \& Chanda, S. V. (2007). In vitro antimicrobial activity and phytochemical analysis of some Indian medicinal plants. Turk J Biol (31), 53-58. http://citeseerx.ist.psu.edu/viewdoc/download?doi=10.1.1.465.1644\&rep=rep1\&type=pdf.

Rodrigues, C. G., Ferreira, P. R. B., Oliveira, C. S. M., Júnior, R. R., Valério, H. M., Bramdi, I. V., \& Oliveira, D. A. (2014) Antibacterial activity of taninis from Psidium guineense Sw. (Myrtaceae). Journal of Medicinal Plant Research, (8), 1-5. https://doi.org/10.5897/JMPR2014.5500

Sanlukhe, D. K., Chavan, J. K., \& Kadam, S. S. (1990). Dietary tannins: Consequences and remedies. Boca Raton: CRC Press. 1- 310.

Santana, P., Andreza, R., Leite, V., Sousa, P., Alves, A., Tintino, S., Oliveira, C., Figueredo, F., Rocha, G., Rocha, M A., Pereira, B., Costa, R, Rodrigues, F, Leandro, L., \& Aquino, P. (2016). Efeito antibacteriano e antifúngico de extratos etanólico, hexânico e metanólico a partir de folhas de kalanchoe pinnata (Lam.) pers (Malva Corama) contra cepas multi-resistentes a drogas. Biota Amazônia (Biote Amazonie, Biota Amazonia, Amazonian Biota), 6(1), 64-69. http://dx.doi.org/10.18561/2179-5746/biotaamazonia. 6(1), 64-69.

Santos, S. C., Ferreira, F. S., Rossi-Alva, J. C, \& Fernandez, L. G. (2007). Atividade antimicrobiana in vitro do extrato de Abarema cochliocarpos (Gomes) Barneby \& Grimes. Revista Brasileira de Farmacognosia, 17 (2), 215-219. https://dx.doi.org/10.1590/S0102-695X2007000200014

Sato, M., Tsuchiya, H., Miyazaki, T., Fujiwara, S., Yamaguchi, R., Kureshiro, H., \& Linuma, M. (1996). Antibacterial activity of hydroxychalcone against methicilin - resistance Staphylococcus aureus. International Journal of Antimicrobial Agents, (6), 227 - 231. https://doi.org/10.1016/0924-8579(95)00065-8

Silva, M., \& Aquino, S. (2018). Antimicrobial resistance: a review of the challenges in the search for new treatment alternatives. Revista de Epidemiologia e Controle de Infecção, 8(4), 472-482. https://doi.org/10.17058/reci.v8i4.11580

Silva et al. (2011). Avaliação da atividade antibacteriana de extratos de Annona muricata L. (Annonaceae). Revista de Biologia e Farmácia. (6) 2, 27-36. 